\title{
Mortality Among Patients Admitted To Intensive Care Unit On Weekends And Holidays Compared With Weekdays
}

\author{
Rajesh Panda ${ }^{1}$,L. Deban Singh ${ }^{2}$,Priyadarshani Padhihari ${ }^{3}$, \\ L. Pradip Kumar Singh ${ }^{4}$, N. Ratan Singh ${ }^{5}$, A. Jack Meitei ${ }^{6}$ \\ 1,2,4,5,6 (Department Of Anaesthesiology, Regional Institute Of Medical Sciences, Imphal, India) \\ ${ }^{3}$ (Department Of Community Medicine, Regional Institute Of Medical Sciences, Imphal, India)
}

\begin{abstract}
The first few hours after intensive care unit admission, are crucial to patient outcome. The availability and quality of personnel and technology are often different during weekday as compared to weekends and holidays. So, the current study was undertaken to investigate mortality among patients admitted to intensive care unit on weekends and holidays as compared with weekdays. Data of all the patients admitted on weekends and holidays as well as weekdays were retrieved from the medical records of intensive care unit. Out of 288 admissions in intensive care unit, $12.8 \%$ of the patients were admitted on the weekends and holidays. A total of 72 patients (25\%) died in one year. Maximum death (52.8\%) occurred during night time. In multivariable analyses controlling for the factors associated with mortality, such as age, gender, patients admitted to the intensive care unit on the weekends and holidays had significantly higher adjusted odds of death $(O R=2.49 ; 95 \% C I=1.19-5.22)$, compared with those admitted in the weekdays $(O R=1)$, and patients admitted in the night time had significantly higher adjusted odds of death $(O R=2.11$; $95 \% C I=1.21-3.66)$, compared to those admitted in the day time $(O R=1)$. So, it was concluded that patients admitted on weekends and holidays to intensive care unit were associated with increased mortality, as opposed to patients admitted to intensive care unit during weekdays.
\end{abstract}

Key words: Holidays, Intensive care unit, Weekends, Weekday, Mortality

\section{Introduction}

Patients in the intensive care unit often have multi-organ abnormalities and physiological disarrangements that require timely diagnostic tests and therapies.[1] The first few hours after intensive care unit admission, where a patient's condition is stabilized and treatment plans are formulated, are crucial to patient outcome.[2] Ideally, the critical care unit has to be organized in such a way that optimal treatment is available to all patients all time. However, the availability and quality of personnel and technology are often different during weekdays as compared to weekends and holidays. So, the current study was undertaken to investigate mortality among patients admitted to intensive care unit of the Regional Institute of Medical Sciences (RIMS), Imphal on weekends and holidays as compared with weekdays.

\section{Materials And Methods}

A cross sectional study was conducted in the intensive care unit of Anaesthesiology Department, Regional Institute of Medical Sciences, Manipur among all the patients admitted to intensive care unit from $15^{\text {th }}$ December, 2015 to $14^{\text {th }}$ December, 2016. After getting permission from the authority, data were retrieved from the medical records of intensive care unit. Since data of all the patients admitted in the intensive care unit on weekends and holidays as well as weekdays were retrieved, sample size was not calculated and sampling was not done. Weekends was defined as Sundays and second Saturday of each month, while Monday to Saturday of each week except second Saturday was taken as weekdays. Holidays was selected as per RIMS official calendar. Day time hours were defined as the hours between 6 am and $6 \mathrm{pm}$. Data entry was done in IBM SPSS 21 for Windows. Data collected was checked for errors. Continuous data are presented as median, mean \pm standard deviation. Proportions are presented as number (\%). Comparisons between groups were analyzed by using the Mann-Whitney U test, Chi-square test as appropriate. The association of patient characteristics with ICU mortality was analyzed by multivariate logistic regression. A probability value of $<0.05$ was considered as statistically significant. Approval was obtained from the Research Ethics Board, RIMS, Imphal. Confidentiality was maintained by excluding the identifiers like name and exact locality.

\section{Results}

During the study period, there were 288 patients admitted to intensive care unit. The median age of the patients was 48.5 years with an age range of 1-94 years. Most of the admitted patients were males (59.4\%). The median stay was 4 days. Overall, $12.8 \%$ of the patients were admitted on the weekend and holidays. Most 
$(60.4 \%)$ of the patients were admitted during day time. The primary reason for the intensive care unit admission was central nervous system (cerebro-vascular accident, eclampsia, encephalitis, hydrocephalus, paraplegia, pseudobulbar palsy, traumatic brain injury, seizure etc.) diseases (23.6\%) (Table 1). A total of 72 patients died $(25 \%)$ in one year. Maximum death $(52.8 \%)$ occurred during night time. Main cause of death was sepsis $(31.9 \%)$ followed by cardiovascular failure (26.4\%) (Fig. 1). There were no significant differences in baseline characteristics between patients admitted on weekends and holidays and those admitted on weekdays (Table 2).

Table 1. Causes of admission in intensive care unit $(\mathrm{N}=288)$

\begin{tabular}{|l|c|c|}
\hline \multicolumn{1}{|c|}{ Causes } & Number & Percentage \\
\hline $\begin{array}{l}\text { Central nervous system (Cerebro-vascular accident, Eclampsia, } \\
\text { Encephalitis, Hydrocephalus, Paraplegia, Pseudobulbar palsy, } \\
\text { Traumatic brain injury, Seizure etc.) }\end{array}$ & 68 & 23.6 \\
\hline $\begin{array}{l}\text { Gastro-intestinal system (Hollow viscus perforation, Liver } \\
\text { diseases, Acute gastro-enteritis, Pancreatitis, Ca lung, gall } \\
\text { bladder, stomach, esophagus, tongue etc.) }\end{array}$ & 54 & 18.8 \\
\hline $\begin{array}{l}\text { Respiratory system (Acute respiratory distress syndrome, } \\
\text { Aspiration Pneumonia, Empyema, Foreign body in throat, }\end{array}$ & 49 & 17.0 \\
Laryngeal Cancer, Lung cancer etc) & & \\
\hline $\begin{array}{l}\text { Genitourinary system (Post-partum haemorrhage, Acute renal } \\
\text { failure, Ca cervix, Ectopic pregnancy, Obstructive uropathy, } \\
\text { Ovarian cyst mass, Chronic kidney disease etc) }\end{array}$ & 33 & 11.5 \\
\hline $\begin{array}{l}\text { Others (Blunt trauma, Poisoning, amputation of limb, Drowning, } \\
\text { Hanging, Myocardial infarction, nasal polyp, Patent ductus } \\
\text { arteriosus, Sepsis, SLE nephritis, tetanus, Scrub typhus etc.) }\end{array}$ & 84 & 29.1 \\
\hline
\end{tabular}

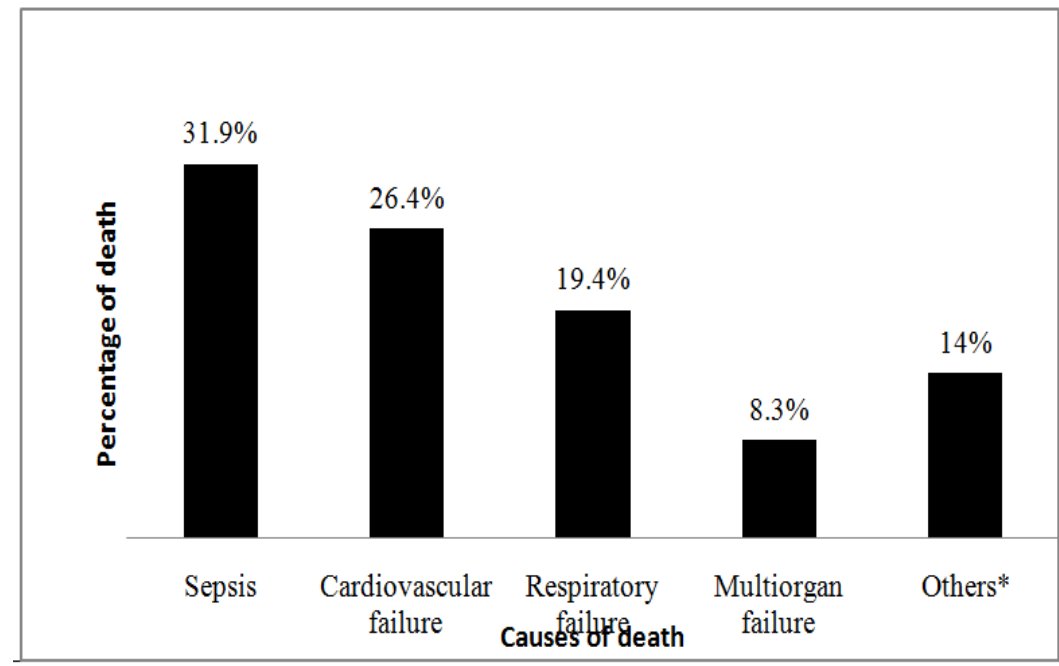

*Others- Acute renal failure, aspiration pneumonia, disseminated intravascular coagulation, intracranial hemorrhage, shock etc.

Fig 1. causes of death in intensive care unit patients $(\mathrm{N}=72)$

Table 2. Demographic characteristic of the study population admitted in weekdays versus weekend and holiday

\begin{tabular}{|l|c|c|c|c|}
\hline \multicolumn{1}{|c|}{ Variables } & $\begin{array}{c}\text { Total patients } \\
\text { admitted (N=288) }\end{array}$ & $\begin{array}{c}\text { Patients admitted } \\
\text { in weekdays } \\
(\mathrm{N}=37)\end{array}$ & $\begin{array}{c}\text { Patients admitted in } \\
\text { weekends and } \\
\text { holidays } \\
(\mathrm{N}=251)\end{array}$ & p-value \\
\hline $\begin{array}{l}\text { Median age in } \\
\text { years }\end{array}$ & 48.5 & 48.0 & 51.0 & 0.535 \\
\hline Sex (males) N (\%) & $171(59.4)$ & $148(59.4)$ & $23(59.0)$ & 0.858 \\
\hline
\end{tabular}

In multivariable analyses controlling for the factors associated with mortality, such as age, gender, patients admitted to the intensive care unit on the weekends and holidays had significantly higher adjusted odds of death $(\mathrm{OR}=2.49 ; 95 \% \mathrm{CI}=1.19-5.22)$, compared with those admitted in the weekdays $(\mathrm{OR}=1)$, and patients admitted in the night time had significantly higher adjusted odds of death $(\mathrm{OR}=2.11 ; 95 \% \mathrm{CI}=1.21-3.66)$, compared to those admitted in the day time $(\mathrm{OR}=1)$ (Table 3$)$. There was no significant association between day and time of admission and length of stay of patients in intensive care unit (Table 4). 
Table 3. Association between day of admission, time of admission and mortality of patients in intensive care unit

\begin{tabular}{|l|c|c|c|c|}
\hline Admission time and day & $\begin{array}{c}\text { Death } \\
\text { N }(\%)\end{array}$ & $\begin{array}{c}\text { Survive } \\
\text { N }(\%)\end{array}$ & $\begin{array}{c}\text { Adjusted OR } \\
(95 \% \text { CI })\end{array}$ & p-value \\
\hline Day of admission & $57(22.7)$ & $194(77.3)$ & $2.49(1.19-5.22)$ & 0.015 \\
\hline Weekdays & $15(40.5)$ & $22(59.5)$ & & \multirow{2}{*}{0.008} \\
\hline Weekend and Holidays & $34(19.5)$ & $140(80.5)$ & $2.11(1.21-3.66)$ & \\
\hline Time of admission & $38(33.3)$ & $76(66.7)$ & & \\
\cline { 1 - 3 } Day time &
\end{tabular}

Table 4. Association between day and time of admission and length of stay of patients in intensive care unit

\begin{tabular}{|l|c|c|}
\hline Admission time and day & Median length of stay in days & p-value \\
\hline Day of admission & 3.5 & \multirow{2}{*}{0.839} \\
\hline Weekdays & 4.0 & \\
\hline Weekend and Holidays & & \multirow{2}{|l|}{0.672} \\
\hline Time of admission & 4.0 & 0.1 \\
\hline Day time & 4.1 & \\
\hline Night time &
\end{tabular}

\section{Discussion}

In this study, significantly higher number of death was found among patients admitted during weekend and holidays. Uusaro A et al [3] have shown increased mortality of patients admitted in 18 intensive care units during weekends when compared to weekdays in Finland. In the present study, night time admissions were associated with significantly higher mortality. A multicenter retrospective study carried out in Canada during 2008 by Laupland KB et al [4] has shown increased mortality for patients admitted to intensive care unit at night compared to those admitted during the day but without increasing mortality during the weekends. The study by Luyt CE et al [5], conducted in 23 ICUs in England, Wales and Northern Ireland over 3 years in 2007, did not show a significant difference in the mortality for patients admitted during off hours when compared to those admitted during the day time to intensive care unit. A recent meta-analysis [1] included ten cohort studies; eight evaluated night admissions and six studies evaluated weekend admission that demonstrated that a night admission was not associated with an increased mortality. However, patients admitted over the weekend have a significant increase in the risk of death. Differences in the definitions of day and hours of admission used in different studies, can explain the difference in results between studies. Differences in the delivery of care in hospital during weekend hours due to reduced overall staffing levels, less senior and less experienced staff, and less supervision have all been quoted as possible explanations for the higher mortality which is called as 'weekend effect'. [6] The same reasons can be applied for higher mortality during holidays and night time. In addition, studies have shown that sleep deprivation of physicians is associated with a decline in performance $[7,8]$, which may be a reason for higher mortality at night. Moreover, differences in outcome also depend on pre-hospital factors (how sick they are by the time they arrive in hospital), which is not taken into account in this study.

\section{Conclusion}

The present study found that patients admitted on weekends and holidays to intensive care unit were associated with increased mortality, as opposed to patients admitted to intensive care unit during weekdays. The present study had certain limitations in that the data were collected from a single intensive care unit in one hospital of Manipur. The relative contribution of pre-hospital factors can't be known from this study. Therefore, further work needs to be done on this. Greater attention to weekend care could be obtained using protocols and guidelines by the health care providers. Clinical guidelines are one of the most promising and effective advances for defining and improving the quality of care. [9]

\section{References}

[1]. Cavallazzi R, Marik PE, Hirani A, Pachinburavan M, Vasu TS, Leiby BE, Association between time of admission to the ICU and mortality: a systematic review and meta-analysis, Chest, 138(1), 2010, 68-75.

[2]. Rivers E, Nguyen B, Havstad S, Ressler J, Muzzin A, Knoblich B, et al, Early goal-directed therapy in the treatment of severe sepsis and septic shock, N Engl J Med, 345(19), 2001, 1368-1377.

[3]. Uusaro A, Kari K, Ruokonen E, The effects of ICU admission and discharge times on mortality in Finland, Intensive Care Med, 29(12),2003, 2144- 2148.

[4]. Laupland KB, Shahpori R, Kirkpatrick AW, Stelfox HT, Hospital mortality among adults admitted to and discharged from intensive care on weekends and evenings, J Crit Care, 23(3), 2008, 317-324.

[5]. Luyt CE, Combes A, Aegerter P, Guidet B, Trouillet JL, Gibert C, et al, Mortality among patients admitted to intensive care units during weekday shifts compared with off hours, Crit Care Med, 35(1), 2007, 3-11.

[6]. Maggs F, Mallet M, Mortality in out-of-hours emergency medical admissions -more than just a weekend effect, J R Coll Physicians Edinb, 40, 2010, 115-118. 
[7]. Deary IJ, Tait R, Effects of sleep disruption on cognitive performance and mood in medical house officers, Br Med J, 295,1987, 1513-1516.

[8]. Gaba DM, Howard SK, Patient safety: fatigue among clinicians and the safety of patients. N Engl J Med, 347(16), 2002, 12491255 .

[9]. Borman E, Promoting good medical care, Eur J Intern Med, 15(8), 2004, 540-545. 